\title{
Anotações teórico-metodológicas do trabalho com fontes visuais e audiovisuais em pesquisas com Histórias de Vida e Memoriais de Formação
}

Theoretical and methodological notes on visual and audiovisual sources in researches on Life Stories and Self-referential Memorials

Maria Helena Menna Barreto Abrahão*

Pontifícia Universidade Católica do Rio Grande do Sul

Resumo O texto explicita a reflexão teórica que fundamenta a utilização de fotografias, videofilmes e filmes em pesquisas com Histórias de Vida e Memoriais de Formação. Após referir pesquisas nas quais utilizamos esse suporte desde 1988, laboramos com dois pares complementares de dimensões teóricas da narratividade de fontes visuais e audiovisuais e seu emprego empírico nessas pesquisas, - Subjetividade/verdade e espaço/tempo. Essas dimensões são trabalhadas, com apoio em Barthes (1984), para propor um esforço interpretativo das referidas fontes na compreensão da essência da fotografia, segundo o fotografoe da essência da fotografia segundo o fotografado tramadas à essência da fotografia segundo o pesquisador. Os constructos barthesianos studium e punctum são aplicados à leitura das narrativas do material fotográfico e fílmico de que as pesquisas dispõem, alcançando, no material de análise, a expressão mais radical do puctum barthesiano: a morte real ou representacional do referente que serve às fotos e filmes. A discussão dessas dimensões para a análise de fontes (áudio)visuais é complementada com apoio de diversos autores.

PALAVRAS-CHAVE: Pesquisa (auto)biográfica, Fontes (áudio)visuais, dimensões barthesianas.

Abstract The text explicits the reflection that bases the use of pictures, films
and videofilms as sources in research on Life Stories and Self-re-
ferential Memorials in Teachers' Education. After refering to the
researches in which we use this support since 1988, we work with
two complementary pairs of theoretical dimensions of narratives in
visual and audiovisual sources and their use in such empirical rese-
arch: subjectivity/truth and space/time. These dimensions are worked
grounded in Barthes (1984) to propose an interpretative effort of
these sources to understand the essence of photography according
to the photographer and the essence of photography according to
the photographed person concocted to the essence of photography
according to the researcher. The Barthesian constructs studium and
punctum are applied to reading the narratives of the filmic and pho-
tographic material, reaching the more radical expression of the Bar-
thesian puctum: real or representational death of the referent that
serves the photos and movies. The discussion of these dimensions
for the analysis of (audio) visual sources is complemented with the
support of several other authors.

KEYWORDS: (Auto)biographical research, (Audio)visual sources, Barthesian dimensions. 


\section{Primeiras palavras (ou: para não dizer que não tentei introduzir...)}

Trabalhamos com fotografias e vídeos desde 1988; com filmes desde 2002, nas pesquisas que vimos desenvolvendo com histórias de vida e com memoriais de formação. Além dessas fontes utilizamos, para a produção de dados e informações, narrativas autobiográficas e narrativas de terceiros - orais e escritas -; documentos pessoais, dentre os quais diários e correspondência; matéria publicada; documentos oficiais, além de histórias de vida de relatos cruzados (PUJADAS, 1992). Especialmente quanto às fontes orais e escritas, temos publicações tratando do referencial teórico-metodológico que adotamos para sustentar o processo de pesquisa em desenvolvimento e explicitando o modus operandi com essas fontes, acentuando como, no concreto de nossa prática, elas funcionam articuladamente, tanto no processo de construção de dados e informações como no processo de análise e interpretação desse material, sempre com base naquele referencial (ABRAHÃO, 2004a, 2008a, 2009, 2012a). Apenas recentemente, no entanto, estamos tentando explicitar como entendemos nosso trabalho com fontes (áudio)visuais, o que representa um primeiro esforço, que reconhecemos, ainda incipiente, de exteriorização da reflexão sobre algumas dimensões que, em nosso sentir, podem dizer respeito ao emprego de fotografias, filmes e vídeos em pesquisa (ABRAHÃO, s. d.).

As pesquisas são apresentadas e discutidas em diversos textos por nós publicados. No presente texto, apenas para introduzir a temática a que nos propusemos, relembramos que, de 1988 a 1997, desenvolvemos a pesquisa Relaçóes de Trabalho no Modo Não-formal de Produção e Comercialização de Bens: o princípio educativo subjacente, que elegeu como objeto de estudo elementos educativos sociais e historicamente produzidos/reproduzidos nas relações de trabalho em modo não formal de produção e de comercialização de bens, conhecido como Brique da Redenção. Essa é uma feira cultural, com 280 expositores, dentre antiquaristas, artistas plásticos, artesãos, que se efetiva a cada domingo em Porto Alegre desde 1978. Em 2005, foi concedido a feira o título de Patrimônio Cultural do Estado do Rio Grande do Sul, pela Lei no. 12.344/2005. Em 2012, para honra nossa, o Brique da Redenção (e a referência à essa pesquisa) representou a identidade do V Congresso de Pesquisa (Auto) Biográfica - V CIPA, realizado na PUCRS, Porto Alegre, de 16 a 19 de outubro de 2012. ${ }^{1}$ A pesquisa, que trabalhou com histórias de vida de 29 expositores das diferentes secções, produziu um videofilme, um álbum de fotografias, artigos e um livro (ABRAHÂO,1997). A pesquisa "O Sujeito Singular-Plural: narrativas de vida, identidade, docência e educação continuada de professores (1998 - atual)", caracteriza-se como um estudo longitudinal que acolhe 4 subprojetos e opera especificamente com duas vertentes da pesquisa autobiográfica. A vertente I objetiva: a) proporcionar visibilidade às Histórias de Vida, com a inclusiva história profissional de destacados educadores que fizeram a História da Educação Rio-grandense, pela compreensão das relações educativas e de construção de identidades que ocorreram/ocorrem no processo formativo e de trabalho desses educadores; b) compreender o pensamento e a prática pedagógica inerentes à história da educação Rio-grandense; a vertente II busca: a) Investigar o movimento na construção identitária de professores em formação continuada (graduandos, mestrandos e doutorandos) por meio de narrativas autorreferentes, mediante a construção de memoriais de formação, como instrumento de (auto)formação, de pesquisa e de intervenção (Investigação-Formação); b) instrumentalizar professores para que utilizem 
narrativas autobiográficas na formação docente. Em ambas as vertentes trabalhamos com fotografias, vídeos e filmes. A pesquisa se desenvolve no âmbito do GRUPRODOCI/CNPq/PUCRS e conta com extensa produção: organização de 17 livros; ${ }^{2} 2$ Dossiês; capítulos em livro, no país e no exterior; artigos em periódicos nacionais e internacionais; participações em eventos científicos, no país e no exterior; orientações de teses e dissertações, realização do Seminário Instrumental de Pesquisa I - Histórias de Vida e Seminário Instrumental de Pesquisa II - Investigação-Formação.

\section{Subjetividade/verdade; espaço/tempo: dimensões da narra- tividade fotográfica, videográfica e filmográfica.}

Um dia, há muito tempo, dei com uma fotografia do último irmão de Napoleão, Jerônimo (1852). Eu me disse então, com um espantoque jamais pude reduzir: 'Vejo os olhos que viram o Imperador'. (BARTHES, 1984, p. 11)

Dimensões teóricas I - não obstante, a rica vertente que se ocupa teórica e metodologicamente do que se tem convencionado denominar de métodos visuais e audiovisuais em pesquisa qualitativa, esfera na qual se pode ler a respeito à luz de conhecimentos em diferentes campos como na História, na Antropologia, na Filosofia, na Sociologia, na Arte, na Estética, na Semiótica, ${ }^{3}$ dada a capacidade de espaço do artigo vamos estabelecer o diálogo especialmente com Barthes (1984).

Esse posicionamento não elide que tenhamos nos valido de lições como as de Kossoy (1989), que tão bem analisa a possibilidade de o registro fotográfico ${ }^{4}$ nos informar a respeito de fatos passados, informação essa que não tem o condão de ipso facto responder pela realidade, em virtude de que é da natureza da imagem fotográfica conter, nela própria, realidades e ficções (KOSSOY, 1999), desde que, tanto a feitura como a interpretação da imagem, conforme o paradigma sociocultural utilizado pelo autor, dá-se mediante a tensão entre representação/fato; memória/documento, visível/ oculto, efêmero/perpétuo a ela inerente (KOSSOY, 2007). Essa tensão mostra-se mais visível ao estabelecer-se uma leitura reflexionada do material visual/audiovisual que não elide, ao contrário, conta com a subjetividade daquele que o interpreta, em nosso caso o pesquisador, assim como já esteve sob a influência daquele que elege e enquadra a imagem - o fotógrafo - e da pessoa fotografada que para tanto geralmente se prepara. Entendemos que a fotografia, o filme e o material vídeogravado também se configuram como narrativas; da mesma forma como as narrativas orais ou escritas, a narrativa imagética é construída intersubjetivamente.

Esse chamamento ao intersubjetivo como chave de leitura de uma imagem lembra-nos da figura da câmara clara - a câmara lúcida, que reproduz a imagem sobre uma folha de papel para que possa ser desenhada por alguém - que Barthes opõe à câmara escura que, objetivamente, reproduz a imagem sem necessidade da interferência da pessoa que a admira. Aquela requer a visão subjetiva, sensível do observador de uma imagem, transformado em câmara clara nessa mediação homem/objeto, que busca surpreender a essência da imagem segundo o próprio sistema de referentes, diferente da essência da fotografia segundo o fotógrafo. Nas palavras do autor (BARTHES, 1984, p. 21), esta tem relação com o estênopo, orifício pelo qual o fotógrafo "olha, limita enquadra e coloca em perspectiva o que ele quer 'captar' (surpreender)", o que nos lembra que também da parte do fotógrafo a verdade da imagem é o que foi importante (verdadeiro) para que ele a fotografasse. 
A busca pela essência da fotografia segundo o observador, em nosso caso o pesquisador, leva Barthes a desenvolver uma fenomenologia do sentimento em virtude de que "eu só me interessava pela Fotografia por 'sentimento'; eu queria aprofundá-la, não como uma questão (um tema), mas como uma ferida: vejo, sinto, portanto noto, olho e penso (op.cit. p. 39)". ${ }^{5}$ Por este prisma, vista pela câmara clara, ou seja, segundo a mediação do observador, "no fundo, a Fotografia é subversiva, não quando aterroriza, perturba, ou mesmo estigmatiza, mas quando é pensativa (op.cit. p. 62, grifo do autor)".

A pensatividadede uma fotografia (ou de uma imagem filmada/videogravada) certamente alcança a expressão mais substantiva no momento em que o autor descreve o que denomina de subjetividade absoluta: "A subjetividade absoluta só é atingida em um estado, um esforço de silêncio (fechar os olhos é fazer a imagem falar no silêncio). A foto me toca se [....] nada dizer, [permitir] fechar os olhos, deixar o detalhe remontar sozinho à consciência afetiva (idem, p. 84-85)". Certamente, a consciência dessa subjetividade absoluta na interpretação de uma imagem pelo observador faz o autor reconhecer que o fotógrafo é quem fotografara "minha mãe [....] não sabia que o que ele fixava era a verdade - a verdade para mim (ibidem, p. 163)".

Subjetividade e verdade constructos que, em ciências sociais em geral e em pesquisa (auto)biográfica em particular, são como as duas faces de uma mesma moeda, a ocorrência de uma implica a outra. Tanto o fotografo como o fotografado, "contaminam" a fotografia. Aquele, ao escolher a imagem, ao enquadrá-la, ao estudar a incidência da luz, dá sua "interpretação"; este "prepara-se" para a foto, ao arrumar-se, fazer pose, etc. ${ }^{6} \mathrm{O}$ verdadeiro, ou se quisermos o real, é aquilo que é verdadeiro e real para cada um. Assim, a verdade do fotógrafo, a da pessoa fotografada e a do pesquisador são relativas aos respectivos sistemas de referentes, que informam as percepções que imprimem sentido à imagem. ${ }^{7}$

Ciente da interferência fotógrafo/fotografado na imagem resultante e levando em conta essa condição, o observador (pesquisador) possivelmente terá consciência da própria interferência (a mediação enquanto câmara clara). Nesse processo, ao interpretar não lhe é dado tratar a imagem fotográfica (ou fílmica) tão somente como registro factual; também buscará tratá-la como possibilidade de compreensão de significados, como possibilidade de construção de conhecimento, enfim, já que essa é essencialmente a finalidade da pesquisa, mais ainda quando se trata de pesquisa qualitativa. Esse esforço interpretativo certamente será mais potente se atentar compreender a essência da fotografia segundo ofotógrafo, bem como a essência da fotografia segundo o fotografado aliadas, possivelmente tramadas, à essência da fotografia, segundo opesquisador.

Ao atentarmos para a complexidade dessa análise, convém trazer a descrição que Barthes faz da própria trajetória na busca da essência da fotografia segundo ele próprio. ${ }^{8} \mathrm{O}$ autor (op. cit) descreve o que chamaríamos de dois movimentos do observador, no caso, o pesquisador, quanto a foto em si: a visão de conjunto, mais perceptível, enquanto obra do fotógrafo, inclusive pela admiração do que de artístico ela contém. É o que denomina de studium. Somente o studium, no entanto, não the parece suficiente para chegar à essência da fotografia segundo o pesquisador. ${ }^{9}$ É necessário que a imagem the fale ao sentimento, lhe pareça singular, lhe atraia o olhar para determinados pontos formais, mais indiciários do que explícitos, que lhe faz refletir, que o punge. É o que chama de punctum. ${ }^{10}$ 
A teoria na pesquisa I - Nas fotografias que temos arquivadas de destacados educadores sul-rio-grandenses, nos chama a atenção a beleza do material. São fotos "posadas" e especificamente escolhidas para integrar os livros que contêm a História de Vida desses educadores. ${ }^{11}$ São fotos bem enquadradas, cuidadas, os educadores arrumados em trajes condizentes ou vestindo toga e beca, geralmente postados no escritório de trabalho ou, se e em outras peças da casa, em ambiente bem arranjado. Há um educador que está postado na sala de professores de uma universidade, junto à placa que o homenageia com a utilização de seu nome para ser o patrono dessa sala de convívio do corpo docente. De uma professora que foi a primeira Secretária da Educação do Estado, consta a fotografia em seu gabinete de trabalho. É possível perceber que, nessas fotos, invariavelmente, fotógrafo e fotografado são coadjuvantes no processo. Nota-se, às claras, a essência dessas fotos segundo o fotógrafo e essa essência segundo os fotografados. A essência das fotos segundo o pesquisador, nos provoca o que Barthes (op. cit.) denominou de studium.

De outra parte, nossa atenção é fortemente direcionada para o semblante dos educadores. O olhar é firme, focado e inspira confiança, embora a fisionomia possa ser doce. Ao perscrutar-se-lhes o semblante e a postura corporal (mesmo que não houvesse informações das demais fontes), o observador percebe que se trata de educadores identificados com a profissão. Essa é, em especial, a característica, o pormenor, o indício que aflora aos nossos olhos, que atrai, que nos punge. Consideremo-lo como o punctum!

Em vídeogravação, temos uma fita VHS, hoje transformada em DVD, que é uma entrevista (datada de 1992) de cerca de uma hora de duração, concedida por uma das destacadas educadoras a um jornalista. A época, essa educadora já estava aposentada e foi entrevistada (e filmada) na própria residência. ${ }^{12} \mathrm{O}$ ambiente é a sala de estar, arrumada com móveis de estilo, no sofá estavam instalados, aparentemente de modo confortável, o repórter e a educadora. Nota-se que ela está trajada com esmero, embora estando em casa, e mantém uma postura elegante, não obstante natural. Mantém, também, naturalidade e desenvoltura no falar. A câmera foca, especialmente, nela, mas, em alguns momentos, se desloca para o entrevistador. Em nosso sentir, os elementos descritos nos provocam o studium.

O que nos punge nessa entrevista? Qual o punctum? Permitimo-nos inferir que é o brilho no olhar da educadora quando narra a própria trajetória, ao rememorar fatos que lhe pareceram significativos. Mas não só, também o tom mais forte da voz, quando quer destacar um ponto..$^{13}$ Além disso, quase imperceptível, o olhar que dirige para o porta-retrato com a foto da mãe, já falecida, quando a ela se refere para contar que foi a mãe que a alfabetizou em casa. Igualmente, nos pungeo raciocínio brilhante, a narrativa construída em intriga, numa trama em que o heterogêneo das muitas vivências adquire sentido, conforme nos ensina Ricoeur (1995; 2007), muito embora o entrevistador a tenha interrompido em diversos momentos.

O entendimento de que a narratividade da imagem "contém" nela própria uma essência intersubjetiva, e a tensão entre studium e punctum nos clarificam a articulação dentre as dimensões subjetividade e verdade na compreensão de fotos, filmes e videofilmes que integram nossas pesquisas. 
Dimensões teóricas II - Espaço-tempo ${ }^{14}$ é uma outra dimensão para o estudo com fotografia, filme e videofilme.

Temos trabalhado com essa dimensão quando vimos nos referindo ao tempo nas narrativas (auto)biográficas orais ou escritas que contribuem para a construção das Histórias de Vida de destacados educadores sul-rio-grandenses, ou ainda, quando trabalhamos com memoriais de formação em nossos Seminários de Investigação-Formação com nossos Doutorandos e Mestrandos ou com nossos alunos do Curso de Pedagogia.

Estabelecemos teórica e empiricamente bem como registramos a relação narrativa e a tridimensionalidade do tempo narrado (ABRAHÂO, 2004a, 2012a), conforme inspiração em Ricoeur (op. cit.), em virtude de que o caráter temporal da experiência humana, pessoal/social, é articulado pela narrativa, em especial quando clarifica a dualidade "tempo cronológico" "tempo fenomenológico". A correlação tempo e narrativa em Paul Ricoeur leva a indagar sobre a procedência da narração histórica de uma consciência histórica, em que o presente, o passado e a expectativa do futuro se imbricam numa perspectiva tridimensional. A natureza temporal tridimensional da narrativa responde por rememorarmos o passado com olhos do presente, permitindo prospectar o futuro, razão pela qual o próprio discurso narrativo não procura necessariamente obedecer a uma lógica linear e sequencial (ABRAHÃO 2006). Procura, sim, construir uma totalidade significativa, a qual Ricoeur chama de síntese do heterogêneo, isto é a colocação em intriga, em enredo, fatos ações, vivências. Essa concepção também encontra-se em Bolívar (2001), quando se refere ao trabalho com Histórias de Vida. Ele tem uma expressão muito interessante: fazer da vida uma história que, diferentemente da vida vivida, é uma construção do sujeito da narração que integra, em uma trama com sentido, elementos significativos do passado que possibilitam compreender o presente e projetar o futuro.

Quanto à dimensão temporal da narrativa, no que diz respeito à imagem, não encontramos, na literatura, a configuração tridimensional do tempo narrado, como no caso da narrativa oral ou escrita, mas uma extensão passado-infinito ou, de modo mais drástico, um esmagamento do tempo.

Barthes (op. cit. p.141) revisita o conceito de punctum, antes enunciado como o detalhe de forma que surpreende o observador; agora, não mais como detalhe de forma (ou para além dela), este punctum fala de intensidade; trata-se do "Tempo, [que] é a ênfase dilaceradora do noema ('isso-foi'), sua representação pura", em virtude de que aquilo que a fotografia "reproduz ao infinito só ocorre uma vez: ela repete mecanicamente o que nunca mais poderá repetir-se existencialmente (op.cit, p. 13)". Exemplificando com a foto de um belo jovem condenado à morte, o autor escreve (idem, p. 142):

A foto é bela, o jovem também: trata-se do studium. Mas o punctum é: ele vai morrer. Leio ao mesmo tempo: isso será e isso foi; observo com horror um futuro anterior cuja aposta é a morte. Ao me dar o passado absoluto da pose (aoristo), a fotografia me diz a morte no futuro. $\mathrm{O}$ que me punge é a descoberta dessa equivalência. Diante da foto de minha mãe criança, eu me digo: ela vai morrer: estremeço, tal como o psicótico de Winnicott, por uma catástrofe que já ocorreu. Que o sujeito já esteja morto ou não, qualquer fotografia é essa catástrofe. 
Esse punctum, mais ou menos apagado sob a abundância e a disparidade das fotos de atualidade, pode ser lido abertamente na fotografia histórica: nela há sempre um esmagamento do Tempo: isto está morto e isto vai morrer. (grifos do autor) (1994, p. 93):

Contra esta catástrofe o observador pode rebelar-se como em Benjamin

Mas, na fotografia, surge algo de estranho e de novo: na vendedora de peixes de New Haven, olhando o chão com um recato tão displicente e tão sedutor, preservase algo que não se reduz ao gênio artístico do fotógrafo Hill, algo que não pode ser silenciado, que reclama com insistência o nome daquela que viveu ali, que também, na foto, é real, e que não quer extinguir-se na "arte". ${ }^{15}$

Martins (2008), de modo semelhante, refere-se à fotografia como um artefato eivado de morte, bastando o operador disparar o obturador da máquina como se fora um tiro de uma arma. O referente (mesmo que ainda vivo) já não é mais como no momento em que foi fotografado, além disso, a foto (o suporte) é imóvel, eternizando um instante que não existe mais. Na pose da foto, o referente resta "parado" como parada, sem movimento como a morte, é a fotografia. De outra parte, no caso da imagem videogravada e do filme, o referente, mesmo que não mais vivo, "vivo continua", dado que o suporte preserva a imagem com o movimento dos gestos e da fala. Reconhecemos, no entanto, com base no que acabamos de citar de Barthes, que a pessoa "viva no filme", está morta ou vai morrer.

Essa ideia de finitude do referente (a pessoa, a coisa, a paisagem fotografadas ou filmadas) ${ }^{16}$ pode ser contraposta à infinitude do suporte (a fotografia, a fita videogravada) que podem não só reproduzirem-se em quantas cópias quisermos, infinitamente, e serem infinitamente observadas. ${ }^{17}$ No entanto, principalmente à época em que as fotografias eram efetivadas em estúdios, em que não havia cópias, a vida de uma fotografia deixava de ser infinita, esvaía-se, sobrevindo-lhe a morte, caso não fosse bem cuidada e convenientemente guardada.

A teoria na pesquisa II - No caso do material visual/audiovisual com o qual vimos trabalhando, essas dimensões dão-se a perceber. Algumas de modo mais evidente, outras mais velado.

Acompanhando Barthes, o que nos punge, para além do que foi narrado no item anterior - A teoria na pesquisa I - é o passado/futuro do que foi/do que não será, subsumido no tempo e no espaço, esmagados das fotografias dos destacados educadores, bem como na entrevista videofilmada de uma destacada educadora. As pessoas estavam lá; as pessoas não estarão lá. O punctum, aqui, é a morte real ou representacional do referente.

Santaella e Nöth (2010), nos auxiliam a compreender dimensões temporais mais objetivas na narrativa (audio)visual.

Consideramos como tempo experimentado, inserido na categoria tempo intrínseco ao material (audio)visual, nossa própria interpretação das fotografias e da entrevista videofilmada, que, possivelmente, será diversa daquela de outros observadores, incluindo os próprios educadores, o fotógrafo ou o operador da câmera de filmagem e, ainda, o entrevistador que realizou a entrevista com a destacada educadora. 
O tempo objetivo do material de que dispomos na pesquisa, que em nosso entender é extrínseco à imagem, as fotos que temos estão preservadas, sendo que uma foto de cada educador está publicada, devendo, portanto, esse suporte sofrer menos a ação do tempo; o mesmo acontece com demais fotos que se encontram catalogadas e bem acondicionadas em nosso acervo, embora delas não tenhamos o negativo. Devemos digitalizá-las, portanto. Já a fita videogravada, suporte que contém a entrevista de uma destacada educadora, a nós emprestada pela família para dela fazer cópia, ao colocá-la no aparelho para reproduzí-la, estava danificada. Não era possível perceber a imagem, muito menos o som. ${ }^{18}$

Quanto à enunciação (facção da imagem) nossa experiência não ocorreu na pesquisa com os educadores. As fotografias e a fita nos foram cedidas. No entanto, na pesquisa com as Histórias de Vida dos integrantes do Brique da Redenção, nós efetuamos as fotografias (embora as tenhamos mandado revelar) e gravamos as fitas em vídeo, o que exigiu que também as editássemos, retirando-lhes o acessório. Essa operação pôde nos dar uma ideia das exigências de tempo da facção da imagem.

Nessa relação intrínseco extrínseco, o tempo intersticial, nos parece o mais relevante, no âmbito das pesquisas que vimos realizando. Este, que Santaella e Nöth (op. cit.) consideram como o tempo da percepção. Como nos afeta o tempo da percepção? Tal qual Manguel (2011) ${ }^{19}$ levamos, em todos os casos, algum tempo para perceber pequenos indícios (explícitos ou não) contidos nas imagens. As nossas leituras das narrativas contidas nas fotos e no filme, muitas vezes somente após trianguladas com outras fontes, é que nos alertavam para algo novo, um indício importante para a interpretação que ainda estava latente, mas ainda "não falante".

Em nossas pesquisas, além desses tempos, temos também os diferentes modos da narrativa que conjuga imagem e texto e que, igualmente, suscitam diferentes modos de interpretação desse conjunto.

\section{As imagens nos contam histórias e são constituídas de historicidade (ou: para não dizer que não tentei concluir...)}

Toda a boa história é, está claro, uma imagem e uma ideia, e quanto mais elas estiverem entremeadas melhor terá sido a solução do problema. (Guy de Maupassant). ${ }^{20}$

Relativamente às imagens, dentre as quais Banks (2011, p. 29) refere-se à fotografia, esse autor nos ensina que essas nos contam histórias, talvez inspirado, como Manguel, em Maupassant.

É com esse fundamento que procuramos ampliar a compreensão das fotos e material videogravado que compõem o acervo de que dispomos nas pesquisas realizadas. Sem negarmo-nos a uma análise mais descritiva, possibilitada pela narrativa interna, segundo Banks (op. cit.) buscamos compreendê-los em nível mais exigente, buscando pistas que possibilitem a construção de significações e que pudessem iluminar momentos da vida, da formação e da produção dos destacados educadores, bem como de nossos alunos em Seminário de Investigação-Formação, no âmbito histórico-social dessas vivências. A narrativa externa nos foi possibilitada pela acurada observação que fizemos de modos de trajar, de arrumação de cabelos, de postura, quando tratava-se de 
fotos; acrescida da entonação da voz, da atitude gestual, da força do olhar, no caso do material videogravado, enfim, de uma série de indícios. ${ }^{21}$

Esse olhar analítico operacionalizou-se pelo emprego de Análise Contextual, com base em Santa Marina e Marinas (1994) e Marinas (2007), que conjugou, nessa ótica, a triangulação do material imagético de que dispúnhamos com as demais fontes. (2011, p 21):

Voltando à análise de imagens, cabe uma questão formulada por Manguel

Mas, qualquer imagem pode ser lida? Ou, pelo menos, podemos criar uma leitura para qualquer imagem? E, se for assim, toda a imagem encerra uma cifra simplesmente porque ela parece a nós, seus espectadores, um sistema auto-suficiente de signos e regras? Qualquer imagem admite tradução em uma linguagem compreensível, revelando ao espectador aquilo que podemos chamar de Narrativa com $\mathrm{N}$ maiúsculo?

Após quase uma página de exemplos, a partir das sombras da parede da caverna de Platão, o autor nos indica o caminho possível:

Se a natureza e os frutos do acaso são passíveis de interpretação, de tradução em palavras comuns, no vocabulário absolutamente artificial que construímos a partir de vários sons e rabiscos, então, talvez esses sons e esses rabiscos permitam, em troca, a construção de um acaso ecoado e de uma natureza espelhada, um mundo paralelo de palavras e imagens mediante o qual podemos reconhecer a experiência do mundo que chamamos de real. (op. cit. p. 22-23)

Em nossas pesquisas, quanto aos filtros teóricos que buscamos para a interpretação das imagens em concerto com o conjunto de fontes de outra natureza, a leitura que delas conseguimos realizar, é singular. Quanto a esse aspecto, uma vez mais somos auxiliadas por Manguel (op. cit) que reconhece que o que vemos em uma pintura, por exemplo, é a pintura traduzida nos termos de nossa própria experiência. Afirma, o autor:

Quando lemos imagens - de qualquer tipo, sejam pintadas, esculpidas, fotografadas, edificadas ou encenadas - atribuímos a elas o caráter temporal da narrativa. Ampliamos o que é limitado por uma moldura para um antes e um depois e, por meio da arte de narrar histórias (sejam de amor ou de ódio), conferimos à imagem imutável uma vida infinita e inesgotável (op. cit. p. 27). ${ }^{22}$

Nessa mesma direção, Loizos (2002, p. 140) afirma o que segue:

Uma [...] falácia comum sobre fotografia é de que ela é simplesmente e universalmente acessível a qualquer um do mesmo modo - que ela opera transculturalmente, independentemente dos contextos sociais, de tal modo que todos a verão e entenderão o mesmo conteúdo na mesma fotografia 
Por essa razão o posicionamento teórico-metodológico que norteia o modo como interpretamos o material de análise, no conjunto das narrativas autobiográficas fotos e demais fontes com as quais trabalhamos nas pesquisas, apresenta-se viável em virtude de que acreditamos, com Banks (op.cit.), que a pesquisa científica não elide a subjetividade do pesquisador, de tal forma que no processo de interpretação, complementamos a "comprensión escénica" (Análise de Contexto), já explicitada, com Análise Reflexiva, com base em Banks. Segundo ele, a Análise Reflexiva, de base epistemológica interpretativista, parte do princípio que o próprio investigador age como uma ferramenta com a qual a pesquisa é conduzida, no caso, pelo esforço idiossincrático com o qual analisamos os dados e informações que conseguimos produzir.

Por isto há de se compreender que a resultante do estudo que vimos empreendendo é o constructo da leitura que fazemos. É a nossa leitura que pode ser diferente da compreensão de outro pesquisador. Entendemos, e nisso somos apoiadas por diversos epistemólogos, que: em pesquisa qualitativa o pesquisador não tem a preocupação (nem a necessidade) de explicar o fenômeno objeto de seu interesse e estudo, mas de compreendê-lo. Essa compreensão depende, naturalmente, do filtro teórico adotado pelo pesquisador, que deve, sim, dar a conhecer seu sistema de referentes, o que sempre temos procurado fazer.

\section{Referências}

ABRAHÃO, M. H. M. B. Fuentes visuales y audiovisuales en la investigación (auto)biográfica - notas teóricas y metodológicas. In: ABRAHÃO, M. H. M. B.; BOLÍVAR, A. (Orgs.). La investigación (auto)biográfica en educación: Brasil y España. Granada: Univ. de Granada; Porto Alegre: EDIPUCRS (no prelo).

. Autobiographical research: Memory, time and narratives in the first person. European Journal for Research on the Education and Learning of Adults, v. 3, p. 29-41, 2012a.

. (Org.). Memórias Memoráveis: educadores sul-rio-grandenses em histórias de vida. Portoa Alegre: EDIPUCRS/Ed. IPA, 2012b.

O método au tobiográfico como produtor de sentidos: a invenção de si. Actualidades Pedagógicas, Bogotá D. C., Colombia, nº. 54, julio-diciembre, p. 13-28, 2009.

. Le récit autobiographique - temps et dimensions de l'invention de soi. In: SOUZA, E. C. (Org.). Autobiographies, Écrits de Soi et Formation au Brésil. Collection Histoire de Vie et Formation - Dirigée par Gaston Pineau, Paris: L'Harmattan,2008a, p. 125-146.

.(Org.). Educadores Sul-Rio-Grandenses: muita vida nas histórias de vida. Porto Alegre: EDIPUCRS, 2008b.

. As narrativas de si ressignificadas pelo emprego do método autobiográfico. In: SOUZA, E. C.; ABRAHÃO, M. H. M. B. (Orgs.). Tempos, narrativas e ficções: a invenção de si. 1 ed. Porto Alegre: EDIPUCRS, 2006, p. 149-170.

. Pesquisa (Auto)Biográfica: tempo, memória e narrativas. In: ABRAHÃO, M.H.M.B. (Org.). A Aventura (Auto) Biográfica - Teoria \& Empiria. Porto Alegre: EDIPUCRS, 2004 a, p. 201-224.

(Org.). Identidade e Vida de Educadores Rio-Grandenses: Narrativas na primeira pessoa (e em muitas outras).Porto Alegre: EDIPUCRS, 2004b.

(Org.). História e Histórias de Vida: Destacados Educadores Fazem a História da Educação Rio-grandense.Porto Alegre: EDIPUCRS, 2001 (2a . ed. 2004). 
. (Org.). Brique da Redenção: Trabalho, Educação, Subjetividade e Saúde em Modo Não-Formal de Produção e Comercialização de Bens. Porto Alegre: EDIPUCS, 1997.

ALBAÏZAR, P.; PICAUDÉ, V. Laconfusióndelosgénerosenfotografía. Barcelona: Gustavo Gili, SA, 2004.

AVANCINI,J.A. Rembrandt e a invenção de si: seus auto-retratos são um percurso autobiográfico? In: SOUZA, E. C. ; ABRAHÃO, M. H. M. B. Tempos, Narrativas e ficções: a invenção de si. Porto Alegre; Salvador: EDIPUCRS; EDUNEB, 2006, p. 119-132.

BANKS, M. Dados visuais para pesquisa qualitativa. Porto Alegre: Artmed, 2011.

BARTHES, R. A câmara clara: nota sobre a fotografia. Rio de Janeiro: Nova Fronteira, 1984.

BAUER, M. W.; GASKELL, G. Pesquisa qualitativa com texto, imagem e som: um manual prático. Petrópolis: Vozes, 2002.

BENJAMIN, W. Pequena história da fotografia. In: BENJAMIN, B. Magia e técnica, arte e política: ensaios sobre literatura e história da cultura. São Paulo: Brasiliense. Obras Escolhidas, 1994, p. 91-107.

BOLIVAR, A. et al. La investigación biográfico-narrativa en educación: enfoque y metodología. Madrid: La Muralla, S. A., 2001.

BRUYNE, P. et al. Dinâmica da pesquisa em Ciências Sociais. Rio de Janeiro: Francisco Alves, 1982.

FABRIS, A. O desafio do olhar: fotografia e artes visuais no período das vanguardas históricas. São Paulo: Martins Fontes, 2011.

FABRIS, A.; KERN, M. L. B. (Orgs.). Imagem e conhecimento. São Paulo: EDUSP, 2006.

GINZBURG. C. Mitos, emblemas, sinais. São Paulo: Companhia das Letras, 2009.

Il formaggio e i vermi. Il cosmo di un mugnaio de '500. Turim: Enaudi, 1976.

JOVCHELOVITCH, S.; BAUER, M. W. Entrevista Narrativa. In: BAUER, M. W.; GASKELL, G. Pesquisa qualitativa com texto, imagem e som: um manual prático. Petrópolis: vozes, 2002, p. 90-113.

KRAUSS, R. O fotográfico. Barcelona: Gustavo Gili, SA., 2002.

KOSSOY, B. Os tempos da fotografia: o efêmero e o perpétuo. Cotia, S.P.: Ateliê Editorial, 2007.

Realidades e ficções na trama fotográfica, São Paulo: Ateliê Editorial, 1999.

Fotografia e história. São Paulo: Ática, 1989.

LOIZOS, P. Vídeo, Filme e Fotografias como Documentos de Pesquisa. In: BAUER, M. W.; GASKELL, G. Pesquisa qualitativa com texto, imagem e som: um manual prático. Petrópolis: Vozes, 2002, p. 137-155.

MACHADO, A. A arte do vídeo. São Paulo: Brasiliense, 1988.

MANGUEL, A. Lendo imagens: uma história de amor e ódio. São Paulo: Companhia das Letras, 2011.

MARINAS, J. M. La escucha en la historia oral. Palabra dada. Madrid: Editorial Sintesis, 2007.

MARTINS, J. de S. Sociologia da fotografia e da imagem. São Paulo: Contexto, 2008.

MAUAD, A. M. O olhar engajado: fotografia contemporânea e as dimensões políticas da cultura visual. Art Cultura.v. 10 n. 16, jan./jun. p. 34-50, 2008, . 
PUJADAS, J. J. Método biográfico: el uso de las historias de vida en ciencias sociales. Madrid: Centro de Investigaciones Sociológicas - CIS, 1992.

RICOEUR. P. A memória, a história, o esquecimento. Campinas, São Paulo: Editora da UNICAMP, 2007.

. Tempo e narrativa. São Paulo: Papirus, 1995,TomoII

SANTAELLA, L; NÖTH, W. Imagem: cognição, semiótica, mídia. São Paulo: Iluminuras, 2010 .

SANTAMARINA, C; MARINAS, J. M. Historias de vida y historia oral. In: DELGADO, J. M. e GUTIÉRRES, J. Métodos y técnicas cualitativas de investigación en ciencias sociales. Madrid: Síntesis, 1994.

V CONGRESSO INTERNACIONAL DE PESQUISA (AUTO)BIOGRÁFICA - V CIPA (2012). Identidade do Evento: BRIQUE da REDENÇÃO. In: <http://www.pucrs.br/ eventos/cipa/?p=capa>, acceso em 12 de septiembre de 2013, a las $8 \mathrm{~h} 40 \mathrm{~min}$.

ZUNZUNEGUI, S. Pensar la imagen. Madrid: Cátedra, 1992.

Notas

${ }^{1}$ (<http://www.pucrs.br/eventos/cipa/?p=capa>, acesso em 12 de setembro de 2013, às 8h40min).

${ }^{2}$ Dentre os quais, quatro bem específicos: Abrahão (2001; 2004b; 2008b; 2012b).

${ }^{3}$ Como se apreende, dentre outros, em Santaella e Nöth (2010), Bruyne et al (1982), Krauss, (2002), Fabris, (2011), Fabris e Kern (2006), Albaïzar e Picaudé (2004), Bauer e Gasktell (2002), Manguel (2011), Martins (2008), Banks (2011), Barthes (1984), Loizos (2002), Mauad (2008), Kossoy (1989, 1999, 2007), Benjamin (1994), Zunzunegui, 1992), Machado (1988).

${ }^{4}$ Conceitos que mutatis mutandis também se aplicam a videofilmes e filmes, em nosso entender. O materialteórico sobre filmes e vídeos é mais restrito, mas essas fontes também integram nossa reflexão no presente texto e serão referidas dentro das possibilidades.

${ }^{5}$ Por esta razão, "Vejo os olhos que viram o Imperador", posto em epígrafe, no início deste item.

${ }^{6}$ Martins (2008) chega mesmo a afirmar que, de um lado, significativas revelações sociológicas se expressam pela atenção do pesquisador ao "vestuário usado como disfarce e maquiagem, como instrumento da ficção da identidade e da auto-imagem [....]; o desencontro visual entre o traje (e o restante do equipamento de identificação) e o corpo constitui um verdadeiro depoimento sobre classe social e o imaginário de classe (p. 15)".

${ }^{7}$ Segundo Martins(2008), "a fotografia é muito mais um documento impregnado de fantasia, tanto do fotógrafo, quanto do fotografado, quanto do 'leitor' de fotografia, do que de exatidões próprias da verossimilhança (idem, p. 28)”. Banks (2011), ao historiaro emprego de fotografias em ciências sociais refere-se: "A fotografia fixa, com sua aparente verossimilhança, foi rapidamente aliada a vários projetos sociológicos.... (grifo nosso, p. 39).

${ }^{8}$ Esta é uma licenciosidade nossa. Barthes não utiliza essa expressão em sentido próprio (pessoal), mas é o que ele faz em toda a extensão do livro. Narra, pari passu, a trajetória intelectual da busca que realiza para a compreensão da fotografia, especialmente a dolorosa busca dessa comprensão em imagens da própria mãe, já falecida. Chega a essa comprensão pela leitura que faz "colocando" studium e punctum em tensão dialética. A descrição desse método é a obra. Esclarece a compreensão desses constructos e os entrelaça na narrativa do esforço de interpretação, a partir da p. 40. 
${ }^{9}$ Da mesma forma, Barthes utiliza a expressão: essência da fotografia segundo o observador.

${ }^{10}$ Uma vez mais, aqui se exemplifica com: "Vejo os olhos que viram Napoleão", que utilizamos como epígrafe.

${ }^{11}$ No presente texto, estamos utilizando o material relativo a fotos de 24 educadores, constantes em Abrahão (2001) e em Abrahão (2004b).

${ }^{12}$ A fita (e, posteriormente, o DVD) integra o acervo constante no GRUPRODOCI, composto de fitas gravadas de narrativas de ex-colegas de estudo e de profissão em diversas funções que a educadora exerceu no Sistema de Ensino do Rio Grande do Sul. Desse acervo constam ainda narrativas de ex-alunos, de amigos e de familiares, além de matéria de jornal, documentos oficiais, fotos e escritos da própria educadora. Essa entrevista é uma joia, em virtude de que, quando iniciamos a construção da História de Vida dessa destacada educadora, ela já havia falecido.

${ }^{13} \mathrm{Na}$ publicação, quando reproduzimos trechos dessa entrevista, colocamos em negrito as palavras e as expressões para representar essa alteração na tonalidade da voz da educadora, no intuito de indicar ao leitor o que representam de entonação na narrativa.

${ }^{14}$ Os elementos teórico-práticos a serem abordados nesse item dirão respeito mais especialmente à dimensão tempo, no entanto sem esquecermos que "toda a imagem fotográfica pressupõe de maneira automática a eleição de um espaço que se decide mostrar e a eliminação simultânea do espaço que fica mais além do enquadramento" (ZUNZUNEGUI, 1992, p. 133). Além disso, muitas vezes, há o espaço geográfico captado na fotografia e, coma mais amplitude, no filme, que podem oportunizar, indícios valiosos de contexto para o esforço de interpretação.

${ }^{15}$ Observamos que nesta citação de Benjamin também se pode visualizar o conceito barthesianode punctumnãosó como algo que nunca poderá repetirse existencialmente (que por esta razão não deseja extinguir-se) mas, também, como o temos conforme o primeiro significado que trouxemos na página 16 de nosso texto: a imagem que lhe fale ao sentimento, lhe pareça singular, lhe atraia o olhar para determinados pontos formais, mais indiciários do que explícitos. (Neste caso, o olhar recatado, displicente e sedutor da vendedora de peixes ).

${ }^{16}$ Não só porque lhe sobrevêm a morte, oportunamente, mas também porque, a partir do instante seguinte ao qual foi fotografada, e com o correr do tempo, vai sofrendo mutações nessa direção.Avancini (2006) em texto que analisa os 86 autorretratos pintados por Rembrandt, o faz historicamente, situando-os no tempo/ espaço/condições socioeconômicas, mas, também, vai deixando perceber as mudanças físicas pelas quais passa o artista.

${ }^{17}$ Anteriormente, desde que se guardassemconvenientementeos negativos; hoje, ainda com maiorespossibilidades desde a fotografia em tecnologia digital; quanto às fitas de vídeo, podem ser copiadas em DVD, por exemplo.

${ }^{18}$ É possível imaginar nosso desespero! A educadora já havia falecido. Esta era a única possibilidade de ouvir a narrativa de vida feita por ela. Cheia de cuidados, confiamos a fita a um técnico que a "limpou", creio que de fungos adquiridos com o tempo, restituindo-lhe a imagem e o som. Extrema felicidade! Tínhamos a educadora, como se viva estivesse e pudesse falar conosco. Pudemos copiar a fita, interpretar omaterial, contando com suas inflexões de voz, com seu sorriso, sua postura pessoal, o brilho de seu olhar. Ao término da entrevista ela toca, a pedido do entrevistador, uma peça de Chopin. Posteriormente, com o advento do DVD, mandamos gravar a fita nesse suporte que possibilitará tê-la indefinidamente. Mesmo assim, houve algum desgaste. Em alguns (poucos instantes) a fita reconstituída pelo técnico, deixou algumas lacunas (poucas) na imagem, permanecendo somente a voz, o que, naturalmente, permaneceu na cópia em DVD.

${ }^{19}$ Em relação a uma pintura de Van GOGH, uma paisagem marinha com barcos, que lhe foi apresentada por uma tia quando Manguel tinha "nove ou dez anos" e da qual nunca esquecera, ao contrário, dela lem- 
brava com frequência, porém, "só vários anos mais tarde fui notar que um dos botes tinha o nome Amitié pintado no casco (MANGUEL, op. cit., p. 25)”.

${ }^{20}$ Citado por Manguel (2011, p. 16).

${ }^{21}$ Nos valemos aquido Paradigma Indiciário, segundo Ginsburg (1976; 2009), que traz à luz as bases do método que lhe é inerente. Trata-se de atentar e valorizar os indícios denotadores de realidades antes desprezados em virtude de que as análises elegiam as tendências gerais do coletivo social, as análises macro-estruturais, por exemplo. Numa outra direção, Ginsburg desenvolve um método em que os indícios ou pistas - imperceptíveis para a maioria - funcionam como chaves para a compreensão de realidades socioculturais complexas, possibilitando, ao pesquisador, traduzi-los numa sequência narrativa pela decifração desses indícios, dessas pistas referentes a determinado contexto.

Aqui, inclusive, retorna a dimensão temporal ad infinitum da imagem, já mencionada anteriormente. Diferente, no entanto, porque, desta vez, a vida eterna da imagem não é proporcionada pela conservação do suporte, mas, sim, pela representação que construímos da "história que ela nos conta.

* Professora Doutora da Pontifícia Universidade Católica do Rio Grande do Sul, Porto Alegre, Rio Grande do Sul - Brasil.

\section{Correspondência}

Maria Helena Menna Barreto Abrahão - Pontifícia Universidade Católica do Rio Grande do Sul, Programa de Pós-Graduação/FACED. Av. Ipiranga, 6681, Partenon, CEP: 90619-900 - Porto Alegre, Rio Grande Sul - Brasil.

E-mail:maria-helena@uol.com.br

Recebido em 13 de novembro de 2013

Aprovado em 20 de dezembro de 2013 